\title{
Kuningas Hattušili I testament
}

\author{
Siim Mõttus \\ Tartu Ülikooli ajaloo ja arheoloogia instituudi doktorant \\ siim.mottus@ut.ee
}

\begin{abstract}
Teesid: II eelkristliku aastatuhande Anatoolias eksisteerinud Hetiidi riigi varasemast ajaloost pole säilinud kuigi palju kirjalikke allikaid. Üheks eredamaks näiteks on kuningas Hattušili I testament, mis pakub põgusa pilguheite hetiitide ühiskonda, ajalukku ning tollastesse troonipärilusprobleemidesse. Tekst jutustab, kuidas surivoodil lamav kuningas Hattušili vahetab välja oma senise troonipärija noore Muršili vastu, kuna eelmine ametisse nimetatu ei näidanud endas olevat piisavalt kuninglikke omadusi. Suuresti didaktilise loomuga tekst pakub nii Muršilile kui ka teda ümbritsevatele inimestele juhiseid riigi juhtimise ja igapäevaelu kohta ning toob negatiivsete näidetena välja kuninga lähikondlaste eksimusi. See artikkel esitab testamendi tõlke hetiidi keelest eesti keelde ning pakub selgitavaid kommentaare.
\end{abstract}

Märksõnad: Hattušili I, hetiidid, kuningavõim, pärilus, testament

Teise aastatuhande algul eKr hakkasid indoeuroopa rahvad Anatoolias haarama enda kätte üha rohkem poliitilist võimu. Selles osas saavutas juhtpositsiooni just hetiidi keelt kõnelev kildkond, kes rajas suurriigi ning hakkas konkureerima teiste Vana-Lähis-Ida suurriikidega. Eeskätt Hetiidi Vana riigi (u 1650-1400 eKr) puhul näib tegemist olevat üsnagi muutliku perioodiga, mida ilmestasid välisvaenlaste invasioonid, mässud provintsides ning iseäranis suured õukonnasisesed pinged. Nende olulisim põhjus oli konfliktid kuningavõimu edasikandumise pärast. Samas võib just perioodi algusaega pidada riigi seisukohalt murranguliseks, sest esmakordselt suudeti ennast kehtestada teiste Vana-Lähis-Ida suurvõimude (näiteks Vana-Babüloonia) kõrval. Kuningas Hattušili I (u 1650-1620 eKr¹) laiendas hetiitide mõjuala Anatoolia tuumikust peaaegu igasse ilmakaarde. Väidetavalt olevat juba tema eelkäija ajal viidud riigi piirid Vahemereni, Hattušili aga edendas neid Põhja-ja Lääne-Anatooliasse ning eriti Süüria suunas, millega ta ehk üritas taastada endiseid kaubateid Mesopotaamia ja Anatoolia vahel. On võimalik, et tema haare võis ulatuda isegi Põhja-Mesopotaamiasse. ${ }^{2}$ Hetiidi kuningal oli kogunisti jultumust pidada ennast paremaks ühest teisest suurmehest, Sargon Suurest, Akadi riigi kui maailma esimese teadaoleva impeeriumi loojast. ${ }^{3}$ Hattušili I ajal sai hoo sisse ka hetiidi kirjakultuur ning hakati kirja panema historiograafilisi, mütoloogilisi, rituaalseid ning administratiivseid tekste. Üheks vaieldamatult olulisimaks 
teoseks sellest perioodist on kakskeelne niinimetatud Hattušili I testament. Mõned hetiidi kirjanduse tähtteosed on nüüdseks juba 15 aastat tagasi ilmunud eesti keeles "Muinasaja kirjanduse antoloogias" (Annus 2005: 203-235), ${ }^{4}$ mille tõlkis Jaan Puhvel, hetiidi keele uurimise ilmne suurkuju. Hattušili testament jäi sellest kogumikust paraku välja. See artikkel täidab selle lünga.

Hattušili I tekst, mida tihtipeale tänapäeva ajalookirjanduses tema testamendiks ristitakse, käsitleb tolleaegseid Hetiidi riigi oukonnaintriige ning kuningliku perekonna liikmete omavahelist kemplemist võimu nimel. Kuningas Hattušili I on teksti järgi haigestunud, võib-olla isegi surivoodil, ning kutsunud Kuššara linna ${ }^{5}$ kokku oma tähtsamad alamad ning kuulutab nendele oma otsuse järjekordse troonipärijakandidaadi osas. Oma kirglikku argumentatsiooni ilmestab kuningas tagasivaadetega hetkedele oma elust, kus tema alamad on kuninga tahet ja tarkust eiranud, seades neid hoiatusteks järgnevatele põlvedele.

\section{Tekst}

Teos on üles kirjutatud kakskeelselt - paralleelsete tulpadena on savitahvlil nii akadi- (I ja IV tulp) kui ka hetiidikeelsed (II ja III tulp) versioonid. Meieni on tekst jõudnud kahe suurema tükina (KUB 1.16 ja KUB 40.65). Võrreldes akadikeelsega on hetiidikeelne osa tunduvalt paremini säilinud ja suuremaid lünkasid selles ei ole. Akadikeelsetest tulpadest on paraku säilinud ainult umbes kolmandik ( $\$ 1-7,22-23)$. Sisu poolest on kaks osa võrdsed. Siiski pole meile säilinud versioon originaal ega pärine ka Vana riigi aegsest perioodist. Keeleliselt kätkeb see küll mitmeid arhailise hetiidi keele eripärasid, kuid paleograafiast nähtub, et tegemist on tunduvalt hilisema koopiaga (Güterbock 1964b: 108), pärinedes umbes 13. sajandist.

Tõlke aluseks on võetud Ferdinand Sommeri ja Adam Falkensteini akadi- ja hetiidikeelne väljaanne (Sommer \& Falkenstein 1938: 2-17) ning Cord Kühne hilisem lisandus (Kühne 1972: 257).

\section{Tõlge $^{6}$}

$\S 1$ (ii 1-7) Suurkuningas Tabarna ${ }^{7}$ rääkis tervele armeele ning suurnikele: Olen haigestunud. ${ }^{8}$ Ma kutsusin teile noore Labarna": "Tema istugu (troonil)!" Mina, kuningas, kuulutasin ta oma pojaks. Ma juhendasin teda ning toetasin teda pidevalt. Tema aga näitas endas noorust, mida ei sobi näha. Ta ei poetanud pisaraid. Ta ei olnud armuline. Ta oli kalk ja südametu. 
§ 2 (ii 8-13) Mina, kuningas, pidasin ta kinni ning lasksin ta oma aseme juurde tuua: "Mis see siis olgu! Keegi ei võta enam oma õe last kasvatada." Aga tema ei tunnistanud kuninga sõna. Oma ema, selle mao sõna tunnistas ta aga alati. Tema vennad ja õed saatsid talle külmi sõnumeid ja tema kuulas nende sõnu alati. Mina, kuningas, kuulsin sellest ja tõrelesin temaga.

$\S 3$ (ii 14-19) Küllalt! Ta ei ole enam minu poeg! Tema ema aga ammus veise kombel: "Nad on rebinud minu vasika minu elavast üsast. Nad rikkusid ta. Ja nü̈̈ te tapate ta!” Kuid kas mina, kuningas, tegin talle kurja? Kas ma ei tõstnud teda preestriks? Ma olen teda alati (oma) headuses soosinud. Tema aga ei arvestanud kuninga soovidega. Kuidas tal saaks siis oma südames olla lembust Hattuša vastu?

$\S 4$ (ii 20-25) Tema ema on madu. Ja juhtuks, et ta (Labarna) jääkski kuulama ainult oma ema ja oma vendade ja õdede sõnu. Ta tuleks selleks, et kätte maksta. Ja mis puudutab minu sõjaväge, ülikuid ja teenreid, kes kuninga (eest) seisavad, ta vannuks: "Kuninga pärast nad surevad!" Ta läheks ja hävitaks nad - ta valaks verd ilma hirmuta.

$\S 5$ (ii 26-29) Ja juhtuks, et Hattuša elanike osas ta tuleks ja kellel iganes neid on, võtaks ära veised ja lambad. Ma [lõin?] oma välisvaenlasi ja hoidsin oma maal rahu. Ei tohi asja selleni viia, et ta riigis segadust tekitab.

§ 6 (ii 30-36) Aga nü̈̈d ei saa ta mingil juhul jälle vabana minna. Ma olen nü̈̈d Labarnale, oma pojale,$^{10}$ andnud majapidamise, olen andnud palju põllumaad, olen andnud palju karjaloomi ning andnud palju lambaid, et ta saaks söönuks ja joonuks. Kui ta käitub hästi, võib ta regulaarselt üles (Hattuša linna) tulla. Aga kui ta põhjustab probleeme või kui ta levitab laimu või ässitab, siis ei tohi ta üles (linna) tulla vaid jääb oma kotta.

$\S 7$ (ii 37-41) Nü̈̈d on Muršili minu poeg! ${ }^{11}$ Teda peate te tunnistama ning tema peate te troonile asetama! [---] Lõvi asemele määravad jumalad ainult uue lõvi. Aga ajal, mil sõjavägi käsu saab või mõni mäss probleemseks muutub, teie, minu alamad ja suurnikud, peate minu pojale abiks olema.

$\S 8$ (ii 42-47) Sõjakäigule mingu ta alles kolmandal aastal. Juba praegu teen ma temast kangelasliku kuninga. Niikaua, kui see pole veel nõnda, [---]. Ta on teie kuninga järeltulija. Kasvatage temast endale kangelaslik kuningas. Kui te võtate ta [veel poisina] sõjakäigule kaasa, tooge ta ohutult tagasi. Olgu teie klann ühtne nagu huntidel. [---] Ta alamad olgu nagu ühest emast sündinud.

$\S 9$ (ii 48-52) Üksainus maks, üksainus kops ning üksainus kõrv on teile antud. ${ }^{12}$ Ärge rebige (üksteist) lõhki, ärge olge üksteisele vaenulikud! Keegi ei tohi 
sellest kuninga sõnast üle astuda! Ärgu keegi käitugu Šinahuwa ja Ubariya linnade kombel!13 Laimul ärgu olgu teie seas kohta! Muidu teeb mu poeg teile mida minagi.

$\S 10$ (ii 53-57) Keegi ärgu mõelgu: "Salaja käitub kuningas, kuidas soovib, (öeldes): 'ma pean seda õigeks, kui on nii või ei ole'." Taolist laimu ei tohi kunagi olla. Pigem teie, kes te teate minu sõnu ja tarkust-juhendage minu poega!

$\S 11$ (ii 58-62) Keegi ei tohiks kedagi tagandada ja keegi kedagi ülendada. Vanemad ${ }^{14}$ ärgu kõnelegu (teile): “Kutsusite meid.” Hattuša vanemad ärgu kõnelegu sinuga, (Muršili), ega ka Hatra mees, Hemuwa mees, Tamalkiya mees, Zalpa mees ${ }^{15}$ ega keegi üldisest elanikkonnast.

$\S 12$ (ii 63-67) Vaadelge minu poja Huzziya juhtumit - mina, kuningas, tegin temast Tappaššanda linna valitseja. Aga nemad (linna elanikud) pidasid ta kinni ning nad levitasid talle laimu ning tegid ta minu vastu vaenulikuks: "Mässa oma isa vastu. Tappaššanda suurtes kodades ei viinud ta läbi puhastusrituaali. ${ }^{16}$ Sina aga pead puhastusrituaali läbi viima.”

$\S 13$ (ii 68-74) Mina, kuningas, võtsin Huzziya kinni. Siis muutusid Hatimaa elanikud ja isegi hattušalased mulle vaenulikuks. Pärast seda pidasid nad kinni minu tütre. Kuna temal oli meessoost järeltulija, olid nad minu vastu vaenulikud: "Sinu isa troonile pole pärijat poega. Keegi alam ${ }^{17}$ hõivab selle, alamast saab kuningas!” Tütar pööras ära Hattuša linna ja suured kojad ustavusest, nõnda et suurnikud ja teenistujad olid mulle vaenulikud. Ta ässitas üles terve maa.

§ 14 (ii 75-81) Vaenus tappis ta [Hattuša?] elanikke [---]. Hattuša elanike osas: kellelt võeti ära veiseid, kellelt lambaid, kellelt viinapuid ning põlde. [---] kes kasutas [---] või härga, siis ka tema [---] ja härg tapeti.

$\S 15$ (iii 1-5) [---] need [---] kuninga alamad [---] ja neid adramehi [---] ja läänimehi ${ }^{18}$ [---] ja nende põllud ta võttis. [---] Aga mina, kuningas ei teadnud (sellest).

$\S 16$ (iii 6-12a) Kui ma aga kuulsin, et ta Hatimaa elanikke tappis, pühkisin ma ära teie pisarad. Kui ma poleks neid pühkinud, oleksite te mind oma keelega laimanud: "Ta ajas oma tütre ära.” Mina, kuningas, ei teinud midagi taolist! Mispeale tütar ütles: "Miks sa oled mulle nii vähe andnud?” Kui ma poleks talle seda vähest andnud, oleksin andnud talle rohkesti veisekarja, rohkesti lambaid, siis oleksin ma joonud (maa) verd. ${ }^{19}$

$\S 17$ (iii 13-22) See tütar teotas minu isikut ja minu nime, seega mina, kuningas, tõin ta Hattušast siia (Kuššarasse). Ma asendasin maa maaga ja veisekarja veisekarjaga. Ta oli hüljanud oma isa sõna ning joonud Hatimaa elanike verd. 
Nü̈̈d on ta aga linnast pagendatud. Kui ta tuleks (taas) minu kotta, lõhestaks ta selle. Kui ta tuleks Hattušasse, põhjustaks ta seal taas mässu. Talle on eraldatud majapidamine maal, kus ta saab süüa ja juua.

$\S 18$ (iii 23-25) Te ei tee talle, (minu tütrele) halba! Tema tegi mulle kurja, aga mina ei maksa talle kurjaga tagasi. Tema ei kutsunud mind oma isaks, mina ei kutsu teda oma tütreks.

§19 (iii 26-32) Hattušas pole keegi senini minu tahtmist järginud. Sina, Muršili, järgi seda! Austa oma isa sõnu. Niikaua kui sa austad oma isa sõnu, sööd sa leiba ja jood vett. ${ }^{20}$ Kui oled veel noores täiskasvanueas, söö kaks või kolm korda päevas ja hoolitse enese eest! Kui aga vanadus sinu südames on - kustuta janu ning heida kõrvale oma isa nõu!

$\S 20$ (iii 33-45) Teie, kes te olete mu tähtsaimad teenrid, te peate järgima minu, kuninga sõnu. Siis sööte te leiba ja joote vett. ${ }^{21}$ Nõnda jääb Hattuša püsima ning maal on rahu. Aga kui te ütlete lahti kuninga sõnadest, ei ole teil enam kauaks elu ning te saate hukka! Kes iganes õonestab kuninga sõna, nüüd [---], ta ei ole enam kõrgem teener. Lõigaku läbi tema [kõri?]!'²2 Ja see ka: kas siis minu vanaisa [---] pojad ei heitnud kõrvale tema sõnu? Minu vanaisa määras Šanahuitta linnas oma poja Labarna (oma pärijaks). ${ }^{23}$ Aga hiljem, tema teenrid ja ülikud seisid tema sõnadele vastu ning asetasid Papahdilmahi ${ }^{24}$ troonile. Kui palju aastaid on möödas ning kui paljud neist on pääsenud? Kus on suurnike kojad? Kas pole need hävinenud?

§ 21 (iii 46-54) Järgige minu, Labarna, suurkuninga sõnu! Niikaua kui te seda teete, jääb Hattuša püsima ning te annate maale rahu. Te sööte leiba ning joote vett. Aga kui te ei ole valvsad, saab teie maa teisele. Olge ka jumalate asjus hoolsad! Olgu nende jäme leib, ohverdamisanumad, nende hautised ja tangud (ohverduste tarvis) valmis. (Muršili, sa) ära lükka (ohverdusi) edasi ega jää nendega maha! Kui sa nendega venitad, järgneb kurjus, nagu vanasti. Nõnda olgu!

§ 22 (iii 55-63) Suurkuningas Labarna kõnetas oma poega (Muršilit): “Olen andnud sulle oma sõnad. Lugegu nad seda tahvlit sinu juuresolekul valjult iga kuu, et sa võtaksid minu sõnad ja tarkuse oma südamesse ning ole minu teenrite ja suurnikutega armuline. Kui sa näed kelleski süütegu - kas keegi eksib jumala ees või keegi ütleb mõne (kohatu) sõna - küsi nõu panku ${ }^{25}$ käest. Ka laimu osas pöördu panku poole. Mu poeg, käitu oma südame järgi.”

§ 23 (iii 64-73) Suurkuningas Labarna kõnetas Haštayari:26 “Ära hülga mind!” Et kuningas ei peaks nõnda rääkima: "paleeteenrid ütlesid: 'See siin (Haštayari) 
peab alati nõu mooridega"27." Kas kuningas tohiks nõnda kõneleda: “Ta (Haštayari) peab ikka veel mooridega nõu, öeldes: 'ma ei tea'?"28 Veel kord, ära hülga mind! Kindlasti mitte! Alati konsulteeri ainult minuga ja ma avaldan sulle oma sõnad. Pese mind, hoia mind oma rinnal ning oma rinnal varja mind maamullaga. ${ }^{29}$

Kolofoon:

Tabarna, suurkuninga tahvel: kui suurkuningas Tabarna Kuššaras haigestus ning juhendas noort Muršilit kuningaks olema.

\section{Selgitused}

Teksti esimesed paragrahvid ( $§ 1-6)$ toovad välja Hattušili I alamate poole pöördumise ja testamendi koostamise ajendi. Hattušili näib olevat oma surivoodil, valmis edasi andma oma valitsejakohustusi. Kuid Labarna, tõenäoliselt kuninga õepoeg, kelle kuningas oli lapsendanud eesmärgiga määrata ta endale troonipärijaks, osutus pettumuseks. Hattušili näeb temas mitmeid valitsejale mittesobivaid omadusi (kalkus, südametus) ning liiga suurt mõju väljavalitule viimase pere poolt. See sektsioon toimib retooriliselt mitmel tasandil. Esmalt peaks see veenma kuninga alluvaid Labarna mittesobivuses ja rõhutama, et viimane oleks alluvatele potensiaalselt otseseks ohuks - seda nii majanduslikus kui ka eksistensiaalses mõttes. Teiseks peaks see looma kontrasti tulevasele kuningale Muršilile kui heale valitsejale, kes lähtub vana kuninga õpetussõnadest. See polnud esimene kord kui Hattušili I valitud troonipärija osutus kõlbmatuks. Ta osutab ka oma pojale Huzzijale (§ 12), kes ebaselgetel põhjustel oma isa vastu mässama hakkas. Lisaks on võimalik, et sama juhtus ka ühe teise Hattušili pojaga - ka Hakkarpili, kes oli saadetud Zalpa linna valitsema, tõusis oma isa vastu üles. ${ }^{30}$

Näib, et troonipärilus oli tollastel aegadel tihtipeale problemaatiline. Palju on ajalookirjanduses diskuteeritud erinevate suktsessioonipõhimõtete konfliktide üle varajases hetiidi ajaloos. Lisaks patrilineaarsusele on võimalike pärilusprintsiipidena arutletud näiteks elektiivse monarhia ning matrilineaarse ja avunkulaarse päriluse üle. ${ }^{31}$ Need oletused rajanevad tihtipeale konjektuuridel ning näevad näiteks võimu kandumist kuninga õepojale või langule pärilusnormina. Kuid kuna enamasti toimusid võimuvahetused, kus mõni kuninga õepoeg või lang troonile sai, vägivaldsel teel, siis võib neid pidada just normi rikkumisteks. ${ }^{32}$ Kuna vägivald oli suunatud kas võimul olevate kuningate endi või siis nende arvatavate poegade vastu, peaks tollaste pärilusprintsiipide rekonstrueerimisel lähtuma ikkagi patrilineaarsusest. Testamendi alguses 
esitatud Hattušili I õepoja kaalumine pärijaks tulenes lihtsalt asjaolust, et kuningal ei olnud enam troonile sobilikke bioloogilisi poegi, sest Huzziyast ja Hakkarpilist oli ta lahti öelnud. Seda ilmestab ka hattušalaste suhu pandud tsitaat: "Sinu isa troonile pole pärijat poega. Keegi alam hõivab selle, alamast saab kuningas!"

Testament kuulutab troonipärijaks noore Muršili (I), kes, nagu me teistest allikatest teame, ka võimule sai ja jäi (valitses u 1620-1590 eKr) kuni tema vastu korraldatud atendaadini aastakümneid hiljem. Ent kui suurt rolli kõnealune dokument reaalselt Muršili võimule saamise osas etendas? Amir Gilan märgib oma monograafias, et kategooria testament on antud teksti kohta küll paslik, kuna see jäädvustab kuninga viimseid sõnu, kuid seda ei tohiks sellegipoolest pidada täielikult juriidiliseks dokumendiks. Toetudes Jan Assmanni teostele väidab ta, et hetiidi arhiividest pole leitud ühtegi aukandja ega ametniku ametisse määramise kirjalikku akti ning leiab, et võimu üleandmine toimus pigem suulise, mitte kirjaliku kommunikatsioonina. Hattušili testament on seega kõigest hilisem toimunu ülestähendamine, vürtsitatud ajaloolistest retrospektiividest ning metafooridest retoorilise efekti saavutamiseks (Gilan 2015: 94-98). Testament ise ei pruukinud Muršilile otseselt võimu anda, küll aga võis seda kindlustada (mõned skeptilisemad ajaloolased on lausa arvanud, et teos koostati just Muršili I enda valitsusajal ning tema käsul eneselegitimiseerimise eesmärgil (Liverani 2004: 37, märkus 16)).

Väljatoomist vajab aga testamendi didaktiline sisu. Suure osa tekstist hõlmavad nii noorele kuningahakatisele kui ka õukonnale mõeldud manitsused ja õpetussõnad. Neile pannakse südamele vana kuninga sõnade ja tahte järgimist ning innustatakse mitte käituma nõnda, nagu seda olid teinud Hattušili I õde, õepoeg, tütar ja poeg. Testament kohustab lausa iga kuu Muršilile neidsamu õpetussõnu ette lugema ( $\$ 22$ ). Didaktilisust ilmestab ka teksti akadikeelne kolofoon, mis võtab lühidalt kokku pöördumise situatsiooni ning eesmärgi: verb uwāru tähendab tõlkes juhendama, käskima, ning seda teksti põhiosa ka teeb - õpetab, kuidas Muršilist saaks hea kuningas. Nõnda oleks ta justkui keskja varauusaegsete vürstipeeglite eelkäija. Paralleele võiks tõmmata ka mõne Vana-Egiptuse didaktilise kirjandusteosega. Ühelt poolt õpetlikkuse poole pealt, näiteks "Õpetusega Merikarele" (tõlget vt Lichtheim 2003), kus juhendatakse kuninga järeltulijat olema hea kuningas ning hoiduma kurja tegemast; teisalt ositi ka Sergei Stadnikovi eesti keelde tõlgitud tekstiga "Amenemhet I õpetus oma pojale Senusertile" (Stadnikov 2014: 39-44). Ka seal designeerib (küll juba atendaadi tõttu teispoolsusesse lahkunud) vana vaarao uue oma järeltulija troonile, hoiatades teda reetlike alamate eest.

Volkert Haas (2006: 65) on välja toonud väga huvitava paralleeli lõiguga Genesisest (1Ms 49: 1-17), kus Jaakob, olles oma elutee lõpus, kuulutab, et tema 
esmasündinu Ruuben kaotab peagi selle staatuse, heidab teistele poegadele Siimeonile ja Leevile ette nende raevukust, eelistades nende asemel Juudat. Muuhulgas kõrvutab Jaakob Juuda lõviga ning Daani maoga, täpselt nagu teeb seda Hattušili Muršili (§ 7: "Lõvi asemele määravad jumalad ainult uue lõvi”) ja oma õe (§ 4: “Tema ema on madu!") osas.

Hattušili kulutab märkimisväärse osa dokumendist enda tegude õigustamisele - miks ta pagendas nii noore Labarna kui ka oma tütre. See on formuleeritud küll otseseks vastuseks eksiili saadetutele, kuid on siiski mõeldud tervele kuulajaskonnale, ning funktsioneerib nii apoloogiana kui ka retoorilise võttena poolehoiu võitmiseks. Apologeetilisi kirjatükke on hetiitidel teisigi. Tuntuimad neist on hilisema nimekaimu teos (niinimetatud Hattušili III apoloogia) ning kuningas Telepinu seadlus, kus mõlemad kaitsevad oma ebareeglipärast võimuletulekut (Hoffner 1975). Lisaks leidub mitmeid tekste, kus hetiidi kuningad põhjendavad näiteks oma sõjaväelisi lüüasaamisi (Singer 2011: 774). Millegi tõttu tundsid sealsed valitsejad vajadust oma tegusid kaitsta, mis on märkimisväärne, võrreldes näiteks Egiptuse vaaraodega, kelle puhul oleks eksimuse tunnistamine tähendanud sisuliselt maailmakorra hävinemist.

Keeleliselt on Hattušili testament väga silmapaistev. See kubiseb värvikatest retoorilistest võtetest - metafooriliselt võrreldakse kuningat lõviga (§ 7), püstitatakse retoorilisi küsimusi ( $\$ 20$ : "Kui palju aastaid on möödas ning kui paljud neist on pääsenud?”) ning kasutakse palju otsekõnet. Loomametafoorid olid Hattušili I aegsetes tekstides äärmiselt levinud. Lisaks madude negatiivse$l^{33}$ ning lõvide heroilisele ja võimsale ${ }^{34}$ kuvandile leiab testamendist ka hundid ( 8 ), kes on karjaloomadena ühtsuse võrdkuju ning ka veised, keda tõstetakse esile nende valju hääle pärast (§ 3). Samuti peab silmas pidama, et testamendi narratiiv pole üles ehitatud ajaliselt lineaarselt. Sealsed ajaloolised osised lisati mitte historiograafilistel eesmärkidel, vaid retoorilisteks eksemplumiteks, et kontraste luues legitimeerida kuninga tahet uue troonipärija valimisel ${ }^{35}$ Seega eelnesid Hattušili poja ja tütre mässamised õepoja Labarna troonipärijaks nimetamisele; kaugeim hetk narratiivis on aga põgus tagasivaade Hattušili vanaisa valitsusaega - kõik ühendatud kuninga alamate poole pöördumise optimistliku õhustikuga raamistikus. Nõnda varieerib autor teksti tooniga, segades negatiivseid ja positiivseid elemente (de Roos 2001: 403-404).

Hattušili I testament on kahtlemata Hetiidi riigi vanema perioodi üks kirjanduslikke tippteoseid. Hõlmates nii didaktilisi, juriidilisi ning ka apologeetilisi jooni ning kasutades ära historiograafilisi osiseid ning ohtraid retoorilisi võtteid publiku veenmiseks, annab see ka olulise sissevaate tollasesse kuningakotta ning kuningavõimu probleemidesse. 


\section{Tänusõnad}

Tänusõnad Vladimir Sazonovile ja Jaan Puhvelile asjalike märkuste ning Eleri Aedmaale keeletoimetamise eest.

\section{Lühendid}

$\mathrm{CTH}=$ Catalogue des textes hittites. Paris. 1971 (https://www.hethport.uni-wuerzburg. de/CTH/ - 1. veebruar 2021).

$\mathrm{KBo}=$ Keilschrifttexte aus Boghazköi. Leipzig \& Berlin (https://www.hethport.uni-wuerzburg.de/kbo/ - 1. veebruar 2021).

KUB = Keilschrifturkunden aus Boghazköi. Berlin.

\section{Kommentaarid}

1 Keskmise kronoloogia järgi; vt Bryce 2005: xv; hetiidi ajaloo kronoloogia probleemide kohta vt Bryce 2005: 375-392.

${ }^{2}$ Sealne Tikunani riik ja selle valitseja paistab olevat olnud Hattušili mõju all; vt Bryce 2005: 78-80.

${ }^{3}$ Hattušili I annaalides on kirjas: "Keegi polnud Eufrati ületanud. Aga mina, suurkuningas tabarna, tegin seda. Ma ületasin selle jalgsi ning minu sõjavägi ületas selle minu järel jalgsi. Sargon ületas selle. Ta võitles Hahha linna armeega, kuid ei teinud midagi Hahhale. Ta ei põletanud seda maatasa - (selle) suits polnud tormijumalale näha. Aga mina, suurkuningas tabarna, hävitasin Haššuwa ja Hahha ning põletasin need maha. Ma näitasin nende suitsu päikesejumalale ja tormijumalale. Ma seadsin Haššuwa ja Hahha kuningad vankri ette"; KBo 10.1 iii 29'-42' (CTH 4). Hattušili I annaalide ingliskeelset tõlget vt Beckman 2006: 219-222; vt ka Güterbock 1964a ning eesti keeles Sargoni kohta Sazonov 2008.

4 Teisi eesti keelde tõlgitud hetiidi tekste vt Puhvel 2001; Sazonov 2011a; Sazonov 2019.

5 Hattušili I ajal oli riigi pealinnaks Hattuša, mis asus praeguse Boğazkale asula lähistel, umbes 150 kilomeetrit Ankarast idas. Testamendi sündmused leiavad aga aset Kuššaras - linnas kust pärines valitsev dünastia. Kuššara linna varemeid pole veel avastatud.

${ }^{6}$ Nurksulud tähistavad tekstis lünki kiilkirjatahvlil, ümarsulud autori selgitavaid lisandusi.

7 Labarna (esines ka kujul tabarna) oli üks tähtsaimaid hetiidi kuningatiitleid, mis oli käibel ka isikunimena. Arvatakse, et tiitel kujuneski välja Hattušili I eelkäija Labarna I nimest, samamoodi nagu Julius Caesari nimest sai hiljem keisritiitel (vt täpsemalt Sazonov 2011b). Testamendis on see kasutusel mõlemas funktsioonis. Ka kuninganna tiitel tawananna võis tuleneda Labarna I kuninganna nimest. Suurkuninga tiitel (tähistati sumerogrammiga LUGAL.GAL), vahest kõige levinum hetiitide kuningatiitel, oli üle võetud Mesopotaamiast ning selle kasutamisega pretendeeriti teiste VanaLähis-Ida suurvõimudega (Babüloonia, Egiptus, Assüüria) võrdsele positsioonile.

8 Ajaloolaste seas on üldlevinud arvamus, et testament jäi sisuliselt Hattušili I viimasteks sõnadeks, mille järel ta "sai jumalaks" (nagu hetiitidel oli kombeks kuninga surma 
kohta öelda). Tema haiguse põhjuseks võis olla sõjakäik Aleppo linna vastu Süürias, sest tekstifragmendist KBo 3.57 ii 10'-11' (CTH 11) võib lugeda: "ja ta (Muršili) läks Halpa (=Aleppo) maale ja ta maksis kätte oma isa (=Hattušili I) vere eest."

9 Testamendis on mainitud kolme erinevat inimest, kes kandsid nime Labarna. Esiteks teksti alguses (§ 1-6) nimetatud Hattušili I õepoeg Labarna. Teiseks viitab § 20 tõenäoliselt kaugemale minevikule, Labarna I-le, kelle Hattušili vanaisa oli oma troonipärijaks määranud ning kes ka enne Hattušilit valitses ning kelle nimest võis saada kuningatiitel. Kolmandaks kasutab Labarna nime Hattušili ise ( $\$ 21-23$ ).

${ }^{10}$ Kuigi Hattušili ütleb eelnevates lõikudes oma kasupojast lahti, nimetab ta teda siinkohal taas oma pojaks.

${ }^{11}$ Kuidas Muršili enne adopteerimist ja troonipärijaks määramist Hattušiliga seotud oli, jääb testamendist selgusetuks. Üks palju hilisem vasallileping viitab Muršilile kui Hattušili lapselapsele; vaata KBo 1.16 obv. 11' (CTH 53).

${ }^{12}$ See metafoor tähistab tõenäoliselt kehaosade harmoonilist koostööd (vt Dardano 2002: 342-343).

${ }^{13}$ Pole teada, millega täpselt need linnad hakkama said.

${ }^{14}$ Kohalikud vanemate (LU.MEŠŠU.GI) nõukogud omasid hetiitide riigi algusaegadel üsna suurt administratiivset võimu. Kuid juba Hattušili I ajal toimunud riigiaparaadi laienemisega vähenes nende tähtsus. Seda on näha ka hilisematest hetiitide seadustest, kus neid on mainitud ainult ühes paragrahvis (vt Puhvel 2001: 165, § 171; Klengel 1965).

${ }^{15}$ Kuigi nende linnade kaardile paigutamisega on mõningaid probleeme, võib neid pidada tähtsateks perifeerseteks piirilinnadeks. Sellele viitab ka hetiitide seaduste paragrahv, kus need linnad on mõnedest kohustustest vabastatud, tõenäoliselt eesmärgiga kindlustada nende lojaalsus (vt Collins 1987: 136-141; Puhvel 2001: 164, § 154).

${ }^{16}$ Verbi párkunu on tõlgendatud mitmeti. Otseses tõlkes tähendab see puhastama, mis esineb nii rituaalse kui ka poliitilise puhastamise (opositsioonist) kontekstis (vt Sommer \& Falkenstein 1938: 112-113; Gilan 2015: 74, märkus 276). Ent on ka oletatud, et mässu võis põhjustada hoopis linna maksudest mittevabastamine (vt Beckman 2003: $80 § 12$ ), kuid oletaja ei põhjenda oma mõttekäiku.

${ }^{17}$ Siinkohas on kasutatud ideogrammi ÌR, mille tähendus on üsna lai ning seda kasutati nii mittevabade inimeste kui ka näiteks kuninga vasallide kohta. Eeldatavasti on siin mõeldud, et troonile kardeti tõusvat kedagi, kes polnud pärit kuninga otsesest liinist.

${ }^{18}$ Adramehed (LU.MEŠAPIN.LÁ) olid tõenäoliselt poolvabad talunikud. Läänimehed (LUMEŠ GIŠTUKUL) olid laialivalguva koosseisuga grupp, kes said tasuks mingisuguse töö (algselt tõenäoliselt sõjateenistuse, hiljem laienes see ka teistele töödele) eest jaosmaa.

19 See tähendab maad koormiste ja maksudega kurnanud.

20 Erinevalt tänapäevast oli hetiitidel vee ja leiva peal elamine ihaldatav elustandard.

${ }^{21} \mathrm{Nu}$ NINDA-an èzzašteni wätar=a ekutteni. See väljend omab hetitoloogia ajaloos olulist rolli, kuna see oli esimeseks hetiidikeelseks lauseks, mida hetiidi keele dešifreerija tšehh Bedřich Hroznýl Esimese maailmasõja aegu tõlkida suutis. Sõna leib (NINDA) oli kirjutatud ideogrammina, seega oli selle tähendus teada sumeri tekstidest. Sõna wātar aga sarnanes vägagi inglise sõnale water ja saksa sõnale wasser, mistõttu julges Hrozný oletada, et selle all on mõeldud vett. Oli loogiline järeldada, et seotuna nimisõnadega leib ja vesi võis ezzašteni ja ekutteni puhul olla tegemist verbidega, mis tähendasid sööma ja jooma. Seda arutlust tugevdas jällegi side tänapäeva keeltega võrrelgem neid näiteks saksa verbiga essen ning ladina sõnaga aqua. Hetiidi keele dešifreerimise kohta vaata lähemalt Zamarovský 1971: 81-119. 
${ }^{22}$ Lõikamise objekti tähistav märk on ainult osaliselt säilinud, kuid paljud autorid loevad välja sumerogrammi ÚR - peenis, fallos. Samas on hetiidi allikates väga vähe viiteid karistuseks mutileerimisele ning need seostuvad eelkõige orjade ninade ja kõrvade lõikamisega (vt Puhvel 2001: 167-168, § 95, 99). Kõri läbi lõikamine oleks tõenäolisem karistus, kuigi selle tähenduse grammatiline rekonstruktsioon on keerulisem.

${ }^{23}$ Hattušili viitab tagasi tema võimule eelnevale ajale. Tema vanaisa identiteet on ebaselge (selle probleemi kohta vt nt Beal 2003; Forlanini 2010). Siinmainitud Labarna on arvatavasti Hattušilile eelnenud sellenimeline kuningas. Šanahuittas paistab olevat veel Hattušili I ajalgi võimul separatistlik režiim, kuna Hattušili annaalid märgivad kuninga sõjakäike linna vastu. Esimene neist ebaõnnestus ning Hattušili piirdus ainult linna ümbruse rüüstamisega, kuid teisel korral, pärast poole-aastast piiramist õnnestus tal see vallutada; vt KBo 10.1 i 4'-5', 46'-48' (CTH 4); vt tõlget Beckman 2006: 219-220.

${ }^{24}$ On välja pakutud, et mässumeelne Papahdilmah oli Hattušili I isa (või vend), tulenevalt ühest kuninglikust ohverdusnimekirjast (KUB 11.7 obv. 17'-18' (CTH 661); Beal 2003: 25-26).

${ }^{25}$ Panku tähendab enamasti kõik, terve, kuid lisaks määrsõnale tähistas see ka hetiidi kuninga õukonna assambleed või nõukogu. Selle koosseis ning ka täpne funktsioon jääb allikatest suuresti selgusetuks - sel võis olla mingisugune nõuandev roll ning kuningas Telepinu (u 1525-1500 eKr) ajal lisandus ka mõningane juriidiline võim. Mingit võimu kuninga õiguste piiramiseks aga sel polnud; vaata täpsemalt panku kohta Beckman 1982.

${ }^{26}$ Tõenäoliselt on tegu Hattušili I ühe naisega, kuigi teistest allikatest teame Hattušili kuningannaks olevat Kadduši nimelist naist.

${ }^{27}$ Moorid, vanad naised (SALŠU.GI) olid osalised mitmetes maagilistes rituaalides aga ka ennustamiskunstis (vt Miller 2010: 173-174).

${ }^{28}$ Lõigust on väga raske aru saada ning paljud tõlkijad on seda erinevalt tõlgendanud. Järgin siin Goedegebuure 2006: 227, 261, märkus 278, kes loeb lõigust välja, et Hattušili hoiatab Haštayarit mitte konsulteerima mooridega ning võtma südamesse nende ennustusi, vaid juhinduma üksnes Hattušili tarkusest.

${ }^{29}$ On arvatud, et siinkohal vihjatakse matuserituaalile (vt Beckman 2003: 81, märkus 14).

${ }^{30} \mathrm{KBo} 3.38$ obv. 21'-37' (CTH 3).

${ }^{31}$ Erinevate vaadete kohta hetiidi päriluse osas vt Mõttus 2018: 10-11. Avunkulaarse süsteemi puhul oleks lihtsustatult pärijaks kuninga õepoeg.

${ }^{32}$ Vana riigi aegset tihtipeale vägivaldset kuningatrooni edasiandmist kirjeldab Telepinu seadlus (CTH 19) (vt Puhvel 2005: 205-208; Mõttus 2018).

${ }^{33}$ Madu sümboliseeris hetiitidel tihtipeale kurjust - hiigelmadu Illuyanka oli antagonist müüdis "Illuyanka ja Tešub" (CTH 321) (vt eestikeelset tõlget ja kommentaare Sazonov 2011a). Samuti seostati madusid nõidusega: "Kui vaba mees tapab ussi ja lausub teise nime, annab ta miini hõbedat. Kui ori, surmatakse ta ise" (vt Puhvel 2001: 174, § 170).

${ }^{34}$ Näiteks Hattušili I oma annaalides: "Ma sain Haššuwast jagu nagu lõvi käpaga" ning “Ma põrnitsesin Hahha linna nagu lõvi”; KBo 10.2 ii 19' ja iii 1'-2' (CTH 4) (vt ka Collins 1998).

${ }^{35}$ Oma tekstides olid hetiidi kuningad vägagi varmad oma tegude õigustamiseks ajalugu ära kasutama. Retrospektiivid kuninglikes ediktides ning ka diplomaatilistes lepingutes olid tavalised ning need on suurepärasteks allikateks tänapäeva uurijatele. 


\section{Kirjandus}

Annus, Amar 2005. Muinasaja kirjanduse antoloogia. Tallinn: Varrak.

Beal, Richard H. 2003. The Predecessors of Hattušili I. Beckman, Gary \& Beal, Richard H. \& McMahon, Gregory (toim). Hittite Studies in Honor of Harry A. Hoffner Jr. on the Occasion of His 65th Birthday. Winona Lake: Eisenbraun, lk 13-35.

Beckman, Gary 1982. The Hittite Assembly. Journal of the American Oriental Society 102 (3), lk 435-442 (doi: 10.2307/602295).

Beckman, Gary 2003. Bilingual Edict Of Hattušili I. Hallo, William W. \& Younger, Lawson K. (toim). The Context of Scripture: Monumental Inscriptions from the Biblical World (Vol. II). Leiden: Brill, lk 79-81.

Beckman, Gary 2006. Annals of Hattusili I. Chavalas, Mark W. (toim). The Ancient Near East: Historical Sources in Translation. Oxford: Blackwell, lk 219-222.

Bryce, Trevor 2005. The Kingdom of the Hittites. New York: Oxford University Press.

Collins, Billie Jean 1987. $§ 54$ of the Hittite Laws and the Old Kingdom Periphery. Orientalia 56 (2), lk 136-141.

Collins, Billie Jean 1998. Hattušili I, the Lion King. Journal of Cuneiform Studies 50 (1), lk 15-20 (doi: 10.2307/1360028).

Dardano, Paola 2002. "La main est coupable", "le sang devient abondant": sur quelques expressions avec des noms de parties et d'éléments du corps humain dans la littérature juridico-politique de l'Ancien et du Moyen Royaume hittite. Orientalia 71 (4), lk 333-392.

de Roos, Johan 2001. Rhetoric in the S.C. Testament of Hattusilis I. van Soldt, W. H. (toim). Veenhof Anniversary Volume. Studies Presented to Klaas R. Veenhof on the Occasion of his Sixty-Fifth Birthday. Leiden: Nederlands Instituut voor het Nabije Oosten, lk 401-406.

Forlanini, Massimo 2010. An Attempt at Reconstructing the Branches of the Hittite Royal Family of the Early Kingdom Period. Cohen, Yoram \& Gilan, Amir \& Miller, Jared L. (toim). Pax Hethitica: Studies on the Hittites and Their Neighbours in Honour of Itamar Singer. Wiesbaden: Harrassowitz, lk 115-135.

Gilan, Amir 2015. Formen und Inhalte althethitischer historischer Literatur. Heidelberg: Universitätsverlag Winter.

Goedegebuure, Petra 2006. The Bilingual Testament of Hattusili I. Chavalas, Mark W. (toim). The Ancient Near East. Historical Sources in Translation. Oxford: Blackwell, lk 222-228.

Güterbock, Hans G. 1964a. Sargon of Akkad Mentioned by Hुattušili I of Hुatti. Journal of Cuneiform Studies 18 (1), lk 1-6 (doi: 10.2307/1359335).

Güterbock, Hans G. 1964b. A View of Hittite Literature. Journal of the American Oriental Society 84 (2), lk 107-115 (doi: 10.2307/597096).

Haas, Volkert 2006. Die hethitische Literatur: Texte, Stilistik, Motive. Berlin \& New York: Walter de Gruyter. 
Hoffner, Harry A. 1975. Propaganda and Political Justification in Hittite Historiography. Goedicke, Hans \& Roberts, Jimmy J. M. (toim). Unity and Diversity: Essays in the History, Literature, and Religion of the Ancient Near East. Baltimore: Johns Hopkins University Press, lk 49-62.

Klengel, Horst 1965. Die Rolle der “Ältesten” (LÚMEŠŠU.GI) im Kleinasien der Hethiterzeit. Zeitschrift für Assyriologie und Vorderasiatische Archäologie 57 (1), lk 223-236 (doi: 10.1515/zava.1965.57.1.223).

Kühne, Cord 1972. Bemerkungen zu kürzlich edierten hethitischen Texten. Zeitschrift für Assyriologie und vorderasiatische Archäologie 62 (2), lk 236-261 (doi: 10.1515/ zava.1972.62.2.236).

Lichtheim, Miriam 2003. Merikare. Hallo, William W. \& Younger, Lawson K. (toim). The Context of Scripture: Canonical Compositions from the Biblical World (Vol. I). Leiden: Brill, lk 61-66.

Liverani, Mario 2004. Myth and Politics in Ancient Near Eastern Historiography. London: Equinox.

Miller, Jared L. 2010. Practice and Perception of Black Magic among the Hittites. Altorientalische Forschungen 37 (2), lk 167-185 (doi: 10.1524/aofo.2010.0015).

Mõttus, Siim 2018. The Edict of Telepinu and Hittite Royal Succession. (MA) Tartu: University of Tartu.

Puhvel, Jaan 2001. Hetiidi seadused. Annus, Amar (toim). Muinasaja seadusekogumike antoloogia. Tallinn: Varrak, lk 155-181.

Puhvel, Jaan 2005. Telepinuse seadlus. Annus, A. (toim). Muinasaja kirjanduse antoloogia. Tallinn: Varrak, lk 205-208.

Sazonov, Vladimir 2008. Akkadi kuningavõim kui arhetüüp. Ajalooline Ajakiri 3, lk 195-214.

Sazonov, Vladimir 2011a. Müüt “Illujanka ja Tešub” ja ${ }^{\text {EZEN }}$ purulliyaš pidustused hetiidi religioosse ideoloogia ja kuningavõimu kontekstis. Usuteaduslik Ajakiri 1, lk 143-161 (https://usuteadus.ee/wp-content/uploads/2011\%20(62)/Sazonov.pdf-2. veebruar 2021).

Sazonov, Vladimir 2011b. Tabarna/Labarna - imperiaalse idee reflektsioon ühe Hetiidi kuningliku tiitli näitel. Tuna 14 (2), lk 18-25.

Sazonov, Vladimir 2019. Kuningas Anitta tekst. Idakiri. Eesti Akadeemilise Orientaalseltsi aastaraamat, lk 129-140.

Singer, Itamar 2011. Between Scepticism and Credulity: In Defence of Hittite Historiography. The Calm Before the Storm. Selected Writings of Itamar Singer on the End of the Late Bronze Age in Anatolia and the Levant. Atlanta: SBL, lk 731-766.

Sommer, Ferdinand, \& Falkenstein, Adam 1938. Die hethitisch-akkadische Bilingue des Hattušili I. München: Verlag der Bayerishen Akademie der Wissenschaften.

Stadnikov, Sergei 2014. Amenemhet I õpetus oma pojale Senusertile. Tallinn: Tallinna Ülikooli Kirjastus.

Zamarovský, Voitech 1971. Hetiitide impeeriumi saladuste jälil. Tallinn: Valgus. 


\title{
Summary
}

\section{The Testament of Hattušili I}

\author{
Siim Mõttus \\ Post-graduate student \\ Institute of History and Archaeology, University of Tartu \\ siim.mottus@ut.ee
}

Keywords: Hattušili I, Hittites, kingship, royal succession, testament

From the Hittite kingdom in the Anatolian peninsula of the II millennium, the first known Indo-European-ruled political entity, the so-called bilingual testament of Hattušili I (ca. 1650-1620 BC) has long fascinated modern scholars. This article offers a translation of the original Hittite text into Estonian. The testament describes the turbulent political situation of the state's earlier period, filled with the king's unruly family members and many rebellions. Seemingly on his deathbed, King Hattušili I proclaimed that instead of the young Labarna, the previously designated heir, a new candidate - Muršili - would take his place, due to the former's unkind nature. Labarna had not been the first to oppose Hattušili. His daughter and son had also done that, revolting against their father. The numerous problems related to inheriting the kingship in the early period of Hittite history have also prompted an ongoing discussion about the succession principles in Hittite society. Concerning the literary value, the testament is a masterpiece that incorporates historical exempla, metaphors, similes, direct speech, and rhetorical questions to enforce the king's arguments and to persuade his audience - the upper echelons of the Hittite society. Despite its name, the testament seems to have more didactical than juridical purposes, as the king offers many instructions to his new heir - to be kind, abstemious, pious and, first and foremost, he orders to heed his wisdom and his will. The ones around the new designee are exhorted to be united and supportive to Muršili. As such, the text can be compared to some other proto-Fürstenspiegels, like "The Teaching for King Merikare" form Egypt's Middle Kingdom, but it also bears parallels to Gen 49. All in all, the testament is a remarkable insight into Hittite history and society.

Siim Mõttus on Tartu Ülikooli ajaloo ja arheoloogia instituudi doktorant. Tema peamiseks uurimishuviks on Vana-Lähis-Ida ning eriti Hetiidi riigi ajalugu ning kultuur.

Siim Mõttus is a PhD student at the Institute of History and Archaeology at the University of Tartu. His main topic of interest is Ancient Near East and especially the history and culture of the Hittites.

siim.mottus@ut.ee 